\title{
DESENVOLVIMENTO DE MÉTODOS DE MICROPROPAGAÇÃO PARA PRODUÇÃO DE MUDAS DE BAMBU - Bambusa nutans G.C. WALL EX MUNRO
}

\author{
Jaqueline Figueredo de Oliveira", Eurico Eduardo Pinto de Lemos', Leila de Paula Rezende1. \\ ${ }^{1}$ Centro de Ciências Agrárias, Universidade Federal de Alagoas, BR 104 - Norte, Km 97, Cidade Universitária CEP 57072- \\ 970 , Maceió, AL. \\ “Autor para correspondência: Jaqueline Figueredo de Oliveira, jaquelinefigueredo@hotmail.com
}

RESUMO - O Bambu - Bambusa spp. (Poaceae) é uma planta muito utilizada na confecção de papel, objetos de arte, construção civil e naval, além de servir como alimento e remédio. Seu cultivo tem sido estimulado em Alagoas desde a criação do Instituto do Bambu em 2000, como resultado de uma parceria entre a Universidade Federal de Alagoas e o numa parceira entre a UFAL e o Serviço Brasileiro de Apoio às Micro e Pequenas Empresas (SEBRAE-AL). Dentre as dificuldades encontradas destaca-se aquisição de mudas e de colmos de bambu de espécies adequadas para suprir a demanda para os seus diferentes usos. 0 Laboratório de Biotecnologia Vegetal (BIOVEG) do Centro de Ciências Agrárias da UFAL vem desenvolvendo pesquisas sobre propagação convencional e micropropagação em várias espécies de bambu. Com o objetivo de desenvolver um protocolo para multiplicação in vitro de Bambusa nutans G.C. Wall ex Munro, espécie de interesse no fabrico de papel, artesanato e construção civil, testaram-se os efeitos da adição de fitohormônios (citocininas e auxinas) em meio de cultura de Murashige e Skoog (MS) na brotação e enraizamento de explantes provenientes de sementes. Os resultados mostraram que houve uma equivalência no número de brotações ( 8 a 12 brotos/explante) entre os tratamentos com 0,2 a 0,5 mg.L${ }^{1} \mathrm{TDZ}$ (Tidiazurom) e 5 a $10 \mathrm{mg.L} \mathrm{L}^{-1}$ de BAP (Benzilaminopurina). Na ausência dos fitohormonios ou com $3 \mathrm{mg.L}^{-1} \mathrm{de}$ BAP, o número de brotações foi significantemente menor (2 brotos/explante), mas estas foram significantemente maiores e com maior número de folhas por explantes. A percentagem de enraizamento dos brotos foi influenciada pela presença de AIB (ácido indolbutírico) sendo maior (80\%) na concentração de $2 \mathrm{mg} . \mathrm{LL}^{-1}$.

Palavras-chaves: Hormônios Vegetais, Poaceae, Cultura de Tecidos.

\section{DEVELOPMENT A METHOD TO PRODUCTION BAMBOO PLANTS, Bambusa nutans G.C WALL EX MUNRO, BY MICORPROPAGATION.}

ABSTRACT - The Bamboo-Bambusa spp. (Poaceae) it is a plant very used in the paper making, art objects, building site and naval, besides serving as food and medicine. Your cultivation has been stimulated in Alagoas from the creation of the Institute of the Bamboo in 2000, as a result of a partnership among the Federal University of Alagoas and the in a partner among UFAL and the Brazilian Service of Support to the Personal computer and Small Companies (SEBRAEAL). Among the found difficulties he/she stands out acquisition of seedlings and of stems of bamboo of appropriate species to supply the demand for your different uses. The Laboratory of Vegetable Biotecnologia (BIOVEG) of the Center of Agrarian Sciences of UFAL it is developing researches on conventional propagation and micropropagação in several bamboo species. With the objective of developing a protocol for multiplication in vitro of Bambusa nutans G.C. Wall ex Munro, species of interest in Imanufacture him/it of paper, craft and building site, the effects of the fitohormônios addition were tested (citocininas and auxinas) in middle of culture of Murashige and Skoog (MS) in the brotação and enraizamento of coming explantes of seeds. The results showed that there was an equivalence in the brotações number ( 8 to 12 brotos/explante) among the treatments with 0,2 to $0,5 \mathrm{mg} \cdot \mathrm{L}^{-1} \mathrm{TDZ}$ (Tidiazurom) and 5 to

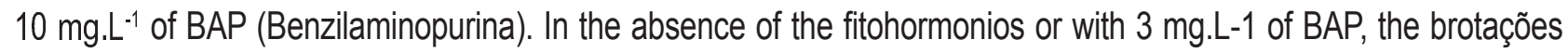
number was smaller significantement (2 brotos/explante), but these were larger significantement and with larger number of leaves for explantes. The percentage of enraizamento of the sprouts was influenced by the presence of AIB (acid indolbutírico) being larger (80\%) in the concentration of $2 \mathrm{mg.L}^{-1}$.

Index Terms: Vegetable Hormones, Poaceae, culture tell. 


\section{INTRODUÇÃO}

As espécies de Bambu, como são conhecidas popularmente, é uma planta do gênero Bambusa, (Poaceae, Babusoideae) (Corrêa, 1984). Na natureza, não existe uma planta que tenha sido mais intensa $\mathrm{e}$ extensivamente utilizada pelo homem. O seu uso, não só nas construções de habitações, como também em pontes suspensas, móveis e artesanatos revelou a incrivel capacidade pré-científica na exploração dos recursos do bambu (Salgado et al., 1986). O bambu vem sendo há muito tempo propagado vegetativamente através de técnicas como 0 desdobramento de touceiras, enraizamento de estacas ou pedaços de colmos e ramos, por ser uma planta de raro florescimento (Salgado \& Godoy Jr., 2002).

Aespécie Bambusa nutans G.C. Wall ex Munro, conhecida como Bambu-lenhoso é originária da Ásia, possui estrutura lenhosa e porte arborescente, apresenta rizoma subterrâneo e colmos aéreos, geralmente fistulosos e articulados (Corrêa, 1984). Os colmos apresentam características que vem sendo aproveitada em várias partes do mundo, servindo como matéria-prima para um diversificado artesanato, que inclui utensílios domésticos, objetos de arte e decoração, sem falar no seu uso para o fabrico de papel, carvão vegetal, reflorestamento, construção civil e naval (Moreira e Ghavami, 1997). Tendo em vista as dificuldades e a demora na obtenção de novas plantas através dos métodos convencionais de propagação vegetativa, surgiu a necessidade da utilização de técnicas de clonagem para acelerar a propagação, de espécies de bambu, destacando-se o cultivo in vitro também conhecido como micropropagação (Manzur, 1981).

Apesar de considerada uma opção importante, há poucos relatos de trabalhos de pesquisas sobre técnicas de micropropagação com diversas espécies de bambu para a propagação massal de clones superiores (Manzur, 1981). O objetivo desse trabalho foi desenvolver um protocolo para multiplicação e enraizamento in vitro de Bambusa nutans. A espécie Bambusa nutans foi escolhida pela facilidade de obtenção de sementes botânicas e por se tratar de espécie semelhante a outras espécies de bambu lenhosas, podendo ser utilizada como balizadora no desenvolvimento de protocolos de micropropagação para outras espécies.

\section{MATERIAL E MÉTODO}

Os experimentos foram conduzidos no Laboratório de Biotecnologia Vegetal (BIOVEG) do Centro de Ciências Agrárias da Universidade Federal de Alagoas em Rio Largo Estado de Alagoas.

\section{Produção de Plântulas}

Sementes provenientes de plantas floradas do Instituto Agronômico de Campinas Estado de São Paulo foram selecionadas, eliminando-se as murchas, para em seguida, passarem por um processo de desinfestação em câmara de fluxo laminar, de acordo com a seguinte sequência: 1) lavagem em $1 \mathrm{~L}$ de água destilada com 3 gotas de detergente comum; 2) lavagem por 10 minutos em fungicida ridomyl $(2 \mathrm{~g}$ $\left.\mathrm{L}^{-1}\right)$; 3) lavagem por 1 minuto em álcool 70\% (v/v); 4) lavagem por 30 minutos em solução de hipoclorito de sódio a $0,6 \%$, juntamente com 2 gotas do detergente Tween 80. Ao final de cada etapa, as sementes eram lavadas com água estéril por três vezes.

Após a desinfestação, as sementes foram inoculadas em tubos-de-ensaio contendo $10 \mathrm{~mL}$ de meio MS descrito por Murashige \& Skoog (1962), gelificado com 2,5 g L-1 de "Phytagel" (Gelrite). 0 pH do meio foi ajustado para 5,8 antes da autoclavagem por 20 minutos a $121^{\circ} \mathrm{C}$. O meio de Murashinge e Skoog utilizado para a germinação das sementes, sem reguladores de crescimento, recebeu a designação de MSq. As sementes foram mantidas em sala de crescimento sob intensidade luminosa de cerca de 50 $\mathrm{mmol} \cdot \mathrm{m}^{-2} \mathrm{~s}^{-1}$, proveniente de lâmpadas frias Philips TDL. O fotoperíodo utilizado teve uma fotofase de 16 horas de luz à temperatura foi ajustada para $25 \pm$ $2^{\circ} \mathrm{C}$. A introdução in vitro das sementes de Bambu, em meio MS semi-sólido, proporcionou a obtenção de explantes viáveis para a realização dos experimentos de multiplicação e enraizamento. A taxa de germinação das sementes foi de $70 \%$, aos 15 dias após a inoculação. Foram realizados dois experimentos visando à multiplicação e enraizamento dos explantes.

\section{Experimento para avaliação da multiplicação}

Aos 45 dias após a germinação as plântulas, tiveram suas raízes excisadas com bisturi, em câmara de fluxo laminar, para serem utilizados na instalação do experimento de multiplicação dos explantes, onde foram avaliados os seguintes tratamentos: 1) MSq 
(Testemunha); 2) MS + TDZ (Thidiazuron) 0,2 $\mathrm{mg} \mathrm{L}^{-1} ; 3$ ) MS+ TDZ 0,5 mg L-1; 4 ) MS+ BAP (Benzilaminopurina) $\left.5 \mathrm{mg} \mathrm{L}^{-1} ; 5\right) \mathrm{MS}+$ BAP $\left.10 \mathrm{mg} \mathrm{L}^{-1} ; 6\right) \mathrm{MS}+\mathrm{BAP} 3 \mathrm{mg} \mathrm{L}^{-1}$. As variáveis estudadas foram o número de brotações por explante e o comprimento dos explantes, por serem indicativos da potencialidade de multiplicação.

\section{Experimento para avaliação de indução de raiz}

No experimento foram avaliados o número de raízes e 0 comprimento das raízes por explante, por ser um dos fatores de pegamento dos explantes para aclimatação. Foi utilizado o meio de cultura MS enriquecido com AIB (ácido indolbutírico) nas seguintes concentrações: 1) MS (Testemunha); 2) MS + AIB 1 $\mathrm{mg} \mathrm{L}^{-1}$; 3) MS+ AIB $\left.2 \mathrm{mg} \mathrm{L}^{-1} ; 4\right) \mathrm{MS}+$ AIB $3 \mathrm{mg} \mathrm{L}^{-1}$. Para que as novas brotações alongassem 0 suficiente para serem transferidas para meio de enraizamento, foi necessário primeiro colocá-las em meio MS sem reguladores de crescimento, por 30 dias, quando estas seguiram para os meios de enraizamento. Já os explantes que obtiveram um tamanho acima de $5 \mathrm{~cm}$ não foi necessário a transferência para $0 \mathrm{MS}$, permanecendo no mesmo até a retirada para o meio de multiplicação.

\section{Análise Estatística}

Os experimentos foram conduzidos em delineamento inteiramente casualizado com 10 repetições, 6 tratamentos para o primeiro experimento e 4 para o segundo, sendo cada repetição representada por um tubo de ensaio contendo um único explante.
Após 15 dias da implantação dos experimentos, foram realizadas coletas quinzenais dos dados por um período de 60 dias. As médias dos tratamentos foram comparadas pelo teste de Tukey a $5 \%$ de probabilidade. Semanalmente avaliou-se a ocorrência de contaminações por bactérias e fungos.

\section{RESULTADOS E DISCUSSÃO}

\section{Experimento para avaliação da multiplicação}

Aos 60 dias após a instalação do experimento de multiplicação, verificou-se que as concentrações de 0,2 e $0,5 \mathrm{mg}^{-L^{-1}}$ de TDZ e 5 e $10 \mathrm{mg} . \mathrm{LL}^{-1}$ de BAP promoveram a multiplicação dos explantes em até seis vezes quando comparados a testemunha ( $0 \mathrm{mg} . \mathrm{L}^{-}$ ${ }^{1}$ BAP) e $3 \mathrm{mg}^{-L^{-1}}$ BAP (Tabela1). Lin \& Charg (1998), trabalhando com varias concentrações de TDZ para multiplicação do Bambusa edulis, obteve melhor

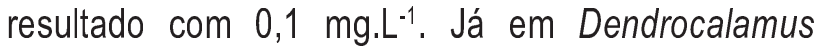
asper a concentração de $3 \mathrm{mg} . \mathrm{L}^{-1}$ BAP promoveu a melhor multiplicação, porem, concentrações acima de $3 \mathrm{mg} . \mathrm{L}^{-1}$ houve uma redução no numero de brotações (Arya et al., 1999).

Observou-se que o TDZ (Tabela 1) se mostrou muito mais efetivo em produzir novas brotações em baixas concentrações do que o BAP. Cid (2000) afirma que existem indicações de que o TDZ seria mais efetivo para multibrotações dos explantes. A ação multiplicativa do TDZ em baixas concentrações tem sido comparada ao efeito de outras citocininas em concentrações muito superiores (Cid, 2000).

Tabela 1 - Médias das diferentes concentrações de TDZ e BAP para multiplicação dos explantes de Bambu (Bambusa nutans).

\begin{tabular}{cc}
\hline Tratamentos & ${\text { Média do } \mathrm{n}^{0} \text { de brotações/explantes * }}^{*}$ \\
\hline MSO (Testemunha) & $2,1 \mathrm{~B}$ \\
MS+TDZ 0,2 mg. $\mathrm{L}^{-1}$ & $12,2 \mathrm{~A}$ \\
MS+ TDZ 0,5mg.L & $9,2 \mathrm{~A}$ \\
MS+ BAP 3mg/L & $2,1 \mathrm{~B}$ \\
MS+ BAP 5mg/L & $8,0 \mathrm{~A}$ \\
MS+ BAP 10mg/L & $11,8 \mathrm{~A}$ \\
\hline
\end{tabular}

Médias seguidas da mesma letra maiúscula não diferem entre si pelo teste de Tukey ao nível de $5 \%$ de probabilidade.

Embora nas condições dos meios de multiplicação contendo TDZ (0.2 e $\left.0.5 \mathrm{mg} \cdot \mathrm{L}^{-1}\right)$ e BAP (5 e $10 \mathrm{mg} \cdot \mathrm{L}^{-1}$ ) os explantes apresentassem elevado número de novos brotos produzidos maior que 8 por explante, estes não se alongaram 0 suficiente para serem individualizados como propágulos sendo menos a $2 \mathrm{~cm}$ (Figura 1). Por isso, as brotações surgidas nos explantes testemunhas e $3 \mathrm{mg} \cdot \mathrm{L}^{-1}$ de BAP com comprimento maior que 5 e $3 \mathrm{~cm}$ respectivamente puderam ser individualizadas e transferidas para meio de enraizamento. 


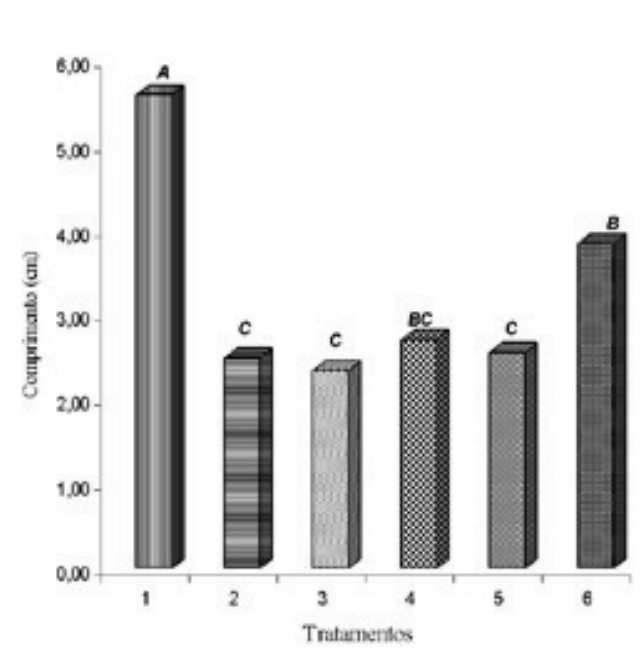

FIGURA 1. Taxa média do comprimento $(\mathrm{cm})$ dos explantes de Bambu - Bambusa nutans - Poaceae. Médias seguidas da mesma letra maiúscula não diferem entre si pelo teste de Tukey no nível de $5 \%$ de probabilidade.

As brotações dos explantes dos tratamentos com TDZ (0.2 e $0.5 \mathrm{mg} . \mathrm{L}^{-1}$ ) e BAP (5 e $10 \mathrm{mg} . \mathrm{L}^{-}$ $\left.{ }^{1}\right)$ só foram individualizadas e transferidas para meio de enraizamento 30 dias após transferência para o meio MS sem a presença de hormônios. Grattapaglia \& Machado (1998) relatam que falta de alongamento e redução no número de folhas em cultura de tecidos vegetais são muitas vezes decorrentes do excesso de citocininas adicionadas ao meio. A contaminação por fungos e bactérias das culturas, que geralmente é causa de transtorno no estabelecimento de espécies vegetais in vitro (George, 1993), foi em média de $5 \%$ na fase de multiplicação.

\section{Experimento para avaliação de indução de raiz}

A porcentagem de enraizamento dos explantes foi diretamente alterada com a adição da auxina AIB ao meio de cultivo, atingindo o seu máximo $(80 \%)$ na concentração de $2 \mathrm{mg}^{-\mathrm{L}^{-1}}$ (Figura 2). De acordo com Arya et al., (1998), o enraizamento de Dendrocalamus asper obteve melhores resultados (98,01\%) com 12 mg. $L^{-1}$ de IBA. Algumas plantas lenhosas são difíceis de enraizar, ou não enraízam, mesmo na presença de auxinas isoladas ou combinadas (Assis e Teixeira, 1998). Nesse trabalho, o comprimento das raízes foi também positivamente influenciado pela adição de 2 $\mathrm{mg} / \mathrm{L}$ de AIB ao meio de cultivo (Figura 3), tendo sido praticamente 0 dobro do valor médio das somas dos outros tratamentos que não apresentaram diferenças entre si.

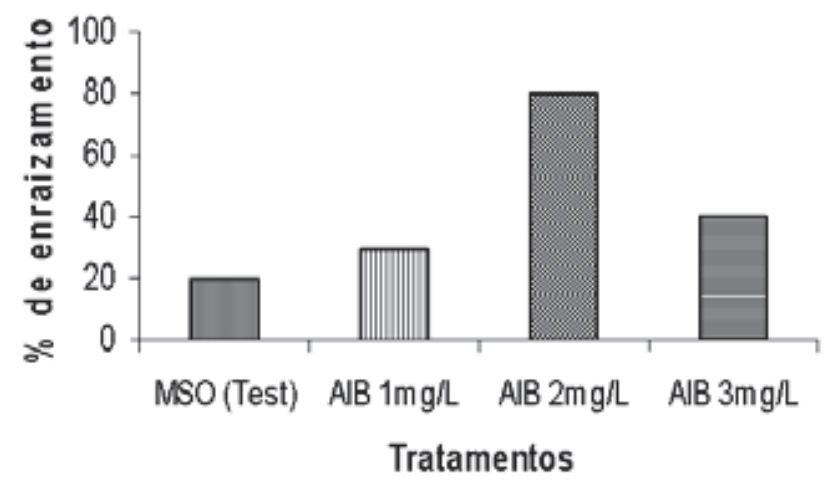

FIGURA 2: Efeito do ácido indol butírico na porcentagem de enraizamento de explantes de bambu (Bambusa nutans) in vitro.

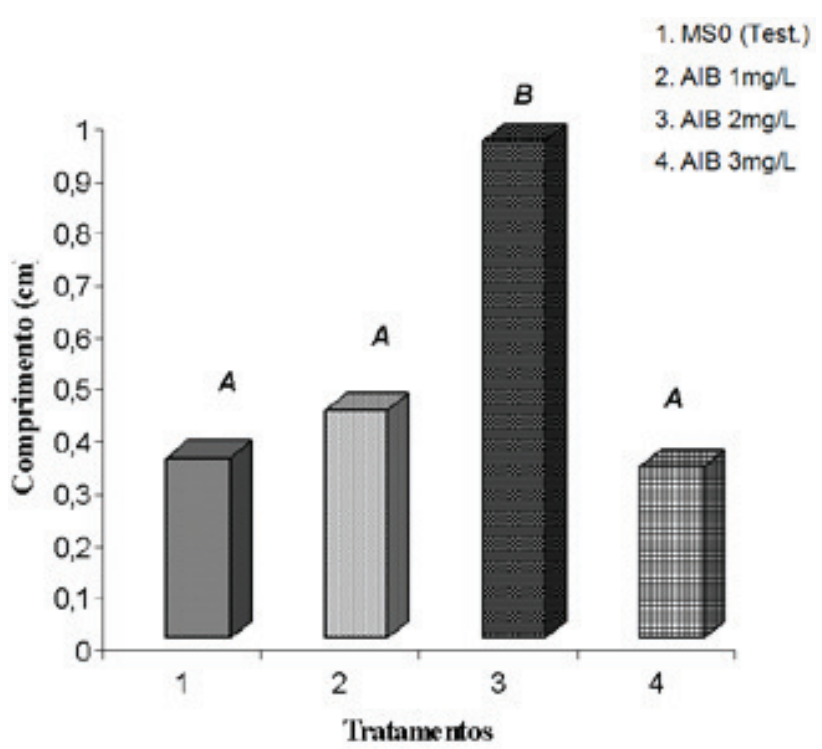

FIGURA 3. Taxa média do comprimento $(\mathrm{cm})$ das raízes dos explantes de Bambu - Bambusa nutans- Poaceae. Médias seguidas da mesma letra maiúscula não diferem entre si pelo teste de Tukey no nível $5 \%$ de probabilidade.

\section{CONCLUSÕES}

O emprego do meio de cultura semi-sólido de MS com adição das citocininas TDZ em baixas concentrações (0,2 e 0,5 mg.L-1 $)$ e BAP (5 e $10 \mathrm{mg} . \mathrm{L}^{-}$ $\left.{ }^{1}\right)$, possibilitou 0 aparecimento de brotações viáveis da espécie Bambusa nutans.

A utilização da auxina IBA na concentração 2 $\mathrm{mg} . \mathrm{L}^{-1}$ proporcionou o maior número e comprimento de raízes por explante.

\section{AGRADECIMENTOS}

Agradeço ao PIBIC-CNPq/UFAL, pela concessão bolsa, ao Serviço Brasileiro de Apoio às Micro e Pequenas Empresas (SEBRAE-AL), Instituto do Bambu 
(INBAMBU) pelos cursos realizados e ao Instituto Agronômico de Campinas (IAC), pela disponibilização do material vegetal.

\section{REFERÊNCIAS BIBLIOGRÁFICAS}

ARYA, S.; SHARMA, S.; KAUR. R.; ARYA, I. D.; Micropropation of Dendrocalamus asper by shoot proliferation using seeds. India. Plant Cell Reports, v.18, p. 879-882. 1999.

ASSIS, T. F.; TEIXEIRA, S. L. Enraizamento de plantas lenhosas. In: TORRES, A. C.; CALDAS, L. S.; BUSO, J.A. Cultura de tecidos e transformação genética de plantas. Brasília: EMBRAPA/CBAB. 1998. p. 261-296.

CID, B. P. L. Introdução aos hormônios vegetais. Brasília: Embrapa Recursos Genéticos e Biotecnologia. 2000. p. 55-81.

CORRÊA, M. P. Bambu. In: Dicionário das plantas úteis do Brasil e das exóticas cultivadas. Rio de Janeiro: Imprensa Nacional, 1984. p.242-247.

GEORGE, E. F. Plant propagation by tissue culture. The technology. Exegetics Limited., London. 1993.574p.

GRATTAPAGLIA, D.; MACHADO, M. A Micropropagação. In: TORRES, A. C., CALDAS, L. S.; BUSO, J. A. (Ed.). Cultura de tecidos e transformação genética de plantas. Brasília: EMBRAPA/CBAB. 1998. p.183-260.
LIN, C. S.; CHANG, W. C.; Micropropation of Bambusa edulis through nodal explants of field-grown culms and flowering of regenerated plantlets. Plant Cell Reports. v.17, p. 617-620. 1998.

MANZUR, M. D. Propagación "In Vitro" de embriones de Bambusa (Bambusa guadua sp.). Costa Rica CATIE Conferência Primer Simposio Latinoamericano Bambu. Manizales, Colômbia. 1981.

MOREIRA, L. E; GHAVAMI, K. Dimensionamento de Estruturas de bambu. Simpósio: "Materiais não Convencionais para a Construção Rural". Campina Grande, Paraíba; UFPB. 1997. p. 237-291.

MURASHIGE., T.; SKOOG, F. A Revised Médium for Rapid Growth and Bioassays With Tabacco Tissue Culture. Physiologia Plantarum, v.15, p. 437-497, 1962.

SALGADO, A. L. de B.; CIARAMELLO, D.; AZZINI, A. Bambu como reforço estrutural em moirões de cerca. 0 agronômico, Campinas, 1986. p. 127-138.

SALGADO, A. L.; GODOY JUNIOR, G. 0 bambu no Brasil: em nossa vida, nossa cultura, seu cultivo e utilização. In: Seminário Internacional-Cursos e Mostra. O uso do bambu na construção civil. Maceió: SEBRAE, 2002. ago. p.39. 